\title{
Социально-исторические и культурные предпосылки формирования сино-европейского стиля в придворной живописи эпохи Цин
}

\begin{abstract}
Аннотация: Объектом рассмотрения в статье является предыстория формирования сино-европейского стиля живописи при дворе династии Цин. Ее предмет - социальные, исторические и культурные предпосылки появления нового стиля. Маньчжурская династия Цин, будучи пришельцами и завоевателями, была менее скована китайскими канонами в искусстве и более восприимчива к европейским влияниям. Но уже в предшествовавшую эпоху в изобразительном искусстве, в том числе и в живописи, проявляются элементы западных влияний, которые также анализируются автором в данной статье. Методами исследования являются общенаучные, а также частнонаучные методы и принципы: сравнительный принцип, принципы историзма, системного анализа, анализ и синтез, индукция и дедукция; социологический, искусствоведческий и семиотический подходы к анализу произведений изобразительного искусства. Основные выводы работы: маньчжуры, покорившие Китай, достаточно быстро «китаизировались» в области искусства. Существовали и предпосылки для формирования сино-европейского стиля в живописи уже при династии Мин. Завоеватели, как это ни парадоксально, во времена династии Цин создали условия для возникновения нового придворного китайского изобразительного искусства. Новизна исследования заключается в утверждении: при встрече двух культур возможно прогрессивное развитие изобразительного искусства высокого художественного значения даже покоренной страны, как это произошло в данном случае, хотя до недавнего времени живопись сино-европейского стиля считалась многими искусствоведами «некитайской», не обладающей оригинальными эстетическими качествами и оставалась практически не исследованной.
\end{abstract}

Ключевые слова: Придворная живопись, эпоха Цин, реализм, шинуазри, «цветы и птицы», погребальный портрет, повествовательная живопись, пейзаж, масляная живопись, линейная перспектива.

Review: The object of the research is the pre-history of the development of Sino-European painting style at the court of Qing dynasty. The subject of the research is the social, historical and cultural background of the new style. Being the foreigners and the conquerors, the Manchu dynasty of Qing was less limited by Chinese canons in art and more susceptible to European influence. However, even during the previous epoch elements of Western influence were manifested in graphic arts including paintings which are also analyzed by the author of the article. The research methods include general scientific methods as well as specific scientific methods and principles such as the comparative principle, historical principles, system-oriented analysis, analysis and synthesis, induction and deduction; sociological, art history and semiotic approaches to analysis of visual artworks. The main conclusions of the research is that Manchurians who had conquered China rather fast became 'Chinese' in the area of art. There had already been a background for the development of the Sino-European style in paintings during Ming dynasty. Conquerors, ironically, created the conditions for the emergence of the new Chinese court graphic arts during Qing dynasty. The novelty of the research is provided by the following statement: when two cultures meet, progressive development of graphic arts of high artistic value is possible even in a conquered country, as it happened in this case, despite the fact that until recently paintings of Sino-European style had been considered as 'non-Chinese' and not possessing the authentic aesthetic features by many of fine art experts and had remained understudied.

Keywords: Linear perspective, oil painting, landscape painting, narrative painting, funeral portrait, 'flowers and birds', chinoiserie, realism, Qing epoch, court painting. 


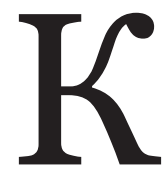

рупное явление в художественной жизни страны, каковым является дворцовая живопись династии Цин, не возникает на пустом месте: в истории, обществе и внутри самой культурной жизни, в первую очередь в живописи, согласно законам ее развития - эволюции и революционных скачков, - складываются определенные предпосылки для рождения нового феномена. В XVII веке в Китае сформировалась своеобразная социокультурная и историческая ситуация, которая и определила уникальное сочетание традиций и новаций в искусстве. Причем Европе Китай впервые открылся именно по цинским произведениям искусства, на основе такой рецепции и сформировалась мода на т.н. «китайщину» (шинуазри). М.А. Неглинская полагает, что формирование шинуазри оказало глубокое воздействие на искусство и в целом культуру Европы, а западную «китайщину» и современный ей вариант цинского стиля периода трех правлений можно рассматривать в качестве полярностей, которые образуют единство более высокого уровня. В итоге «китайская культура и искусство оказались подготовлены к тем переменам, которые последовали в XX столетии при образовании единого пространства мировой культуры» [1, с. 468 - 470]. В самой Поднебесной цинское художественное творчество при дворе до недавнего времени оценивалось невысоко, а потому не было исследовано достаточно глубоко.

Приступая к изложению темы, следует сделать одно методологически важное замечание. Понятие «реализм» в китайской культуре понимается шире, чем «отражение жизни в формах самой жизни»: сюда включают и правдивое изображение реальных лиц и событий при необязательно реалистической (с европейской точки зрения) форме, хотя с западных художников и искусствоведов это недостаточный и даже необязательный признак реалистического изобразительного искусства.

Что же происходило в истории Китая в XVII и XVIII столетиях?

Правитель династии Цин был родом из малой народности Китая, выходцем из племени чжурчжэней в Цзяньчжоу с фамилией Айсинь Цзюэло (Айсин Гёро) ${ }^{1}$. Представитель династии оказался последним феодальным

\footnotetext{
${ }^{1}$ Айсинь Цзюэло, или Айсин Гёро - одна из фамилий императорской семьи последней маньчжурской династии Китая; в переводе означает «Золотой клан».
}

самодержцем в истории Китая, а также преемником династии Юань. В 1616 г. Нурхаци (правил в 1616-1626 гг.) основал правящую династию с официальным названием государства Цзинь и столицу в Хэту-ала. В 1625 г. власти перенесли столицу в г. Шэньян, изменив название на Шэнцзин. Затем Хуантайцзи (Айсинь Цзюэло - правитель Тайцзи; правил в 1626-1643 гг.) объявил себя императором и одновременно изменил официальное название государства на Дайцин (Великая Цин), а название народа «чжурчжэни» - на «маньчжуры». В 1644 г. император Ши-цзу (Айсинь Цзюэло Фулинь; правил в 1643-1661 гг.) вторгся в Китай. Новые власти перенесли столицу в Пекин, и с этого времени маньчжурская династия сместила династию Мин, начав царствовать во всем Китае. Император Канси (Айсинь Цзюэло Сюанье; правил в 16611722 гг.) усмирил восстание против династии Цин, вернул о. Тайвань, и в итоге маньчжурская династия объединила всю страну. При императоре Юнчжэн (Айсинь Цзюэло Иньчжэнь; правил в 1722-1735 гг.), императоре Цяньлун (Айсинь Цзюэло Хун Ли; правил в 1735 (1736?-1796 гг.) военная смута принесла с собой серьезные разрушения, но вскоре после этого экономическая система постепенно стала развиваться и укрепляться. Этот исторический этап именуется потомками периодом процветания династии Цин и является самым ярким и благополучным периодом правления данной династии. Начиная с императора Цзяцин (Айсинь Цзюэло Юнянь; правил в 17961820 гг.) господство династии Цин начинает стагнировать, правители оказывались один хуже другого, углублялся социальный кризис, постоянно восставали крестьянские массы наступал упадок, свершилась закономерность развития: «подъем - процветание - увядание» [2, с. 3].

В 1911 г. разразилась Синьхайская революция, 12 февраля 1912 г. последний император династии Цин, Пу И (Айсинь Цзюэло Пу И), в Пекине был вынужден устами матери отречься от престола и объявить о завершении правления династии, царствовавшей почти три столетия.

Династия Цин в истории Китая - одна из величайших династий, объединивших всю страну. Ее историческая значимость заключается, прежде всего, именно в исполнении функции «собирания земель». Численность населения при династии Цин в течение ряда поколений по сравнению с другими феодаль- 
ными правящими династиями была наибольшей, к концу эпохи Цин, в 1901 г., она достигла 450 млн. человек. В это время активно осваивались территории, в том числе пограничные, и расширялись границы; так, в период расцвета территория государства превышала 13 млн. км², что фактически являлось самой крупной подконтрольной площадью Китая за все предыдущие периоды. Изменялось в целом геополитическое положение Восточной Азии. Бедные люди перебирались на восток к Заставе Шаньхайгуань, на запад в район Великой Китайской стены близ Шаньси, в провинцию Синьцзян, превращая пограничные районы в районы компактного проживания ханьцев, для Китая расширялось пространство маневрирования при отпоре колонизаторам. Династия Цин осуществляла комплексную национальную политику, обеспечивая сплоченность национальных меньшинств на центральной равнине.

Хотя маньчжуры и господствовали в Китае в военной и политической областях, однако в сфере гуманитарной, напротив, во многом поддержали культуру ханьцев, позволили культуре Китая продолжать традиции преемственности и развития и, в конце концов, достигнуть роскошной кульминации; их мотивы и культурные стремления заслуживают глубокого изучения [см.: 3, с. 9]. С одной стороны, пришедшие к власти маньчжуры довольно быстро китаизировались: с другой, не скованные жесткой китайской традицией, они были открыты принятию новаций в искусстве; с третьей стороны, те китайские художники прежней эпохи, которые не были согласны с новым режимом и не желали сотрудничать с завоевателями, ушли в монастыри, как, например, художники Хун Жэнь, Кунь Цань, Чжу Да и Юань Цзи, оставшиеся в истории как «четыре монаха», или иначе стали вести отдельное, провинциальное, маргинальное, приватное существование как скитальцы и более дворцовой живописью не занимались. Все это создавало благоприятные условия для появления нового феномена - дворцовой реалистической живописи эпохи Цин.

В эпоху династии Мин (1368-1644), предшествовавшей династии Цин, Китай, освободившись от монгольских завоевателей, вновь превращается в самостоятельную державу и переживает период интенсивного роста и расцвета. Китайцы возвращаются к традициям домонгольской эпохи, укрепляют национальную систему социального управления.
Для страны в эпоху Мин, воцарившуюся после падения династии Юань, характерны гигантские строительные проекты. Возводятся большая часть Великой Китайской стены, Пекин и его Запретный Город, очищается и удлиняется Великий Канал длиной 2470 километров.

По времени правление династии Мин совпадает с эпохой Возрождения в Европе. Правда, Европа ставила задачу «возродить» Античность (в том виде, в каком она ее себе представляла), а Поднебесная, естественно, такой задачи не знала. Тем не менее, социокультурный контекст и некоторые художественные веяния, появившиеся в ту пору, были созвучны на Востоке и на Западе, в Европе и в Китае.

В Поднебесной вновь появилась мода на изображение придворных дам, а меж тем этот жанр, начиная с периода династии Тан, не был востребован. В целом живописцы ориентировались на древние образцы, и прежде всего на искусство эпохи Сун, как, например, крупнейший художник этого времени Мин Вэнь Чжэнмин (1470-1559). Но появились и новации: живопись фигур, эротический жанр. Большим мастером-анималистом был император Чжу Чжаньцзи (1398-1435); по мнению некоторых специалистов, он был единственным минским императором, одаренным настоящим талантом живописца.

Статус художника в эпоху Мин мог быть разным: были и придворные живописцы, и одиночки, и целые самостоятельные школы живописи. Среди многочисленных художников этого периода выделяют четверых художников: Шэн Чжу, уже упомянутого Вэнь Чжэнмина, Тан Иня и Цю Ина.

Жанр «цветы и птицы» доминировал в творчестве художников, принадлежавших к возрожденной на рубеже 20-х - 30-х гг. XV столетия придворной Академии живописи. В этом жанре прославились Бянь Вэньцзинь (работал приблизительно в 1410-1435 гг.) и Линь Лян (ок. 1410-е гг. - 1490-е гг.).

Придворный художник Бянь Вэньцзинь занимал пост в Зале Воинской Доблести, а его произведения отличаются реалистичностью, светлым колоритом и изяществом в работе с тушью. Затем мастер получил пост «дайчжао» в придворной Академии живописи, но в 1426 г. был обвинен во взяточничестве (государственная служба была притягательна для многих), попал в тюремное заключение, где, видимо, и умер. Бянь работал в манере гун- 
би, которая по своей природе тяготела к реализму. Прославились его работы «Три друга и сотня птиц», «Бамбук и журавли» и др. В отношении формы мастер чаще всего избирал большие вертикальные декоративные свитки (как знаменитые «Сто птиц») или писал тушью небольшие монохромные композиции на отдельных листах. Сто поющих птиц - китайский символ мира на земле. Бянь создал вариацию уже известного сюжета: в каталоге императорской коллекции эпохи Сун «Сюаньхэ Хуапу» сообщается о четырех картинах «Сто птиц» авторства сунского придворного художника И Юаньцзи.

Линь Лян, родом из семьи бедняков, учился живописи и стал известен в среде местных чиновников, потом дослужился сначала до должности в министерстве строительства императорского дворца, проживал и работал над своими произведениями в Зале Благожелательности и Мудрости, затем, активно продвигаясь по служебной лестнице, занял должность командира императорских гвардейцев. Чаще всего мастер использовал монохромную технику «свободной руки», работал в жанре «цветы и птицы», в основном на вертикальных свитках. Специалисты отмечают, что Линь Лян учился на творчестве Бянь Вэньцзиня, но стал самостоятельным мастером с уникальным почерком. Сама его манера была близка художникам-интеллектуалам, но они недооценивали его творчество, как обычно недооценивали и все придворное искусство, поскольку оно, мол, «на потребу», «заказное».

В живописи XVI столетия, при преобладании подражания древним мастерам, славились работы Люй Цзи (ок. 1429-1505; работал в должности хранителя императорского гардероба и в конце карьеры - как командир императорских гвардейцев, как Линь Лян) в жанре «цветы и птицы». Мастер трудился с помощниками, создал множество копий работ древних мастеров и выработал собственный стиль, который получил название «минского академического стиля живописи цветов и птиц», но творил и в стиле «свободной руки».

Развивался родившийся в XV веке и тяготевший к яркой реалистичности т.н. «погребальный портрет», а в XVI столетии появляется жанр иллюстрации погребальных произведений. Расцветает повествовательная живопись, которая берет за основу сюжеты литературных произведений; этот жанр получит развитие в т.н. документальных работах следующей эпохи.
В эпоху династии Мин существовали и независимые от дворца художники. Эти мастера трудились преимущественно в жанре пейзажной живописи.

Известны также Школа У во главе с Шэн Чжу (1427-1509), школа Чжэ, ярким представителем которой был Дай Цзинь (род. ок. 1430 г.) и Хуатинская (Сунцзянская) школа во главе с выдающимся теоретиком живописи Дун Цичаном. Сунцзянскую школу следует отметить специально, поскольку она оказала большое влияние на творчество придворных мастеров династии Цин.

Хуатинская (Сунцзянская) школа названа так по городу Хуатин. При династии Мин Хуатин стал одним из крупнейших культурных центров Китая, а сегодня это район Шанхая. Расцвет Хуатинской (Сунцзянской) школы случился в поздний период династии Мин. Интеллектуальным и творческим центром школы стал художник Дун Цичан, его окружение составили мастера со сходными взглядами на историю и современную им живопись, например Мо Шилун (1537-1587), Чэнь Цзижу (1558-1639), Сун Сю (1525 - после 1605), Сунь Кэхун (1532-1611), Чжао Цзо (ок. 1570 после 1633), Шэнь Шичун (работал ок. 16071640 годов) и др. Тут бурлила интенсивная творческая жизнь последователей живописи интеллектуалов (вэньжэньхуа), аудитория слушала доклады по актуальным вопросам художественной жизни. Тут же была сформулирована и теория «северной» и «южной» школ. Основной жанр представителей этой школы - пейзаж. По содержанию их работы являлись вариациями на темы произведений древних авторов. Образованность, доскональное знание творчества предшественников и способность им подражать, создавая версии известных сюжетов, ценились здесь очень высоко. Именно эти особенности данной школы и в целом традиционность изобразительного искусства эпохи Мин дали основание некоторым европейским исследователям и критикам XX столетия утверждать, что живопись этой эпохи неоригинальна, а потому не представляет особого художественного интереса.

После падения династии Мин преемниками художественных идей Хуатинской школы в Сунцзянском регионе стали «Девять друзей живописи», а в цинскую эпоху - «Четверка Ванов» (художники Ван Шиминь, Ван Цзянь, Ван Хуэй и Ван Юаньци).

При династии Мин происходит расцвет и декоративно-прикладного искусства. В нем 
все отчетливее становились видны фольклорные корни, связанные с изначальной китайской идентичностью. Получило развитие и фарфоровое ремесло.

В то же время западноевропейскими мореходами и торговцами, а также миссионерами, осваивается путь в Китай - очень трудно, с отказами императоров принять их, со стычками с местными жителями и гибелью пришельцев.

Вообще говоря, первыми христианскими миссионерами в Китае были несториане в VII веке, а первые католики прибыли сюда в XIII столетии. Но в силу ряда причин особое влияние на китайскую культуру и цивилизацию оказали миссионеры-иезуиты, начиная с XVI века. Правда, к концу XVIII столетия их деятельность запрещают, что не помешало им действовать на полулегальных основаниях. В конце XVII века в Китай проникает и православие [4; 5].

Миссионеры-католики, и прежде всего Маттео Риччи и К. Никола, которые впоследствии взяли себе китайские имена Ли Мадоу и Цяо Вани, как оказалось впоследствии, ознакомили китайцев не столько с христианством, сколько с научными знаниями Европы тех времен и европейскими художественными навыками. Миссионеры не были профессиональными живописцами, но, как и многие представители итальянского Возрождения, так или иначе владели кистью. Именно они научили придворных мастеров Поднебесной технике масляной живописи и гравюры на меди (офорт), приемам классической композиции, показали им европейские сюжеты, светотеневую моделировку и прямую линейную перспективу.

Первым опытом создания масляной картины в Китае стала работа Цяо Вани, написанная в 1583 г. на библейский сюжет. Он же открыл в Поднебесной первый художественный институт западного типа в монастыре Шэн Баолу в Аомыне. Среди китайских учеников Цяо Вани наиболее известны Ни Ягу, Ю Вэньхуэй и Ши Хунцзи.

Деятельность Маттео Риччи (Ли Мадоу; 1552-1610) сделала его самым известным миссионером своего времени. Однако, прибыв в Китай в 1582 г. и скончавшись в Пекине в 1610-м, за все годы пребывания в стране он со своими помощниками сумел окрестить довольно незначительное количество жителей Поднебесной. Его известность, как и в случае с Цяо Вани, связана не с успешностью христианской миссии, а с ролью медиатора между Европой и Азией, европейского ученого, знакомившего китайцев с историей европейской культуры, недурного живописца, на практике обучавшего китайских мастеров технике масляной живописи, почему он и стал востребованным при императорском дворе как художник.

Во многом благодаря деятельности Ли Мадоу, уже начиная с XVII столетия, китайское искусство развивалось в двух разных направлениях - го-хуа и ю-хуа.

Незадолго до своей кончины Ли Мадоу совместно с китайским просветителем Сюе Гуанчи переводит с итальянского языка на китайский несколько работ по математическим дисциплинам: «Теорию геометрии» и «Закон измерения». Эти книги оказали китайским живописцам, в том числе следующей эпохи, чрезвычайно существенную помощь в овладении приемами светотени и линейной перспективы.

Согласно мнению ряда синологов, империя Мин - это конец императорского Китая. Как утверждает известный китаист В.В. Малявин, все богатые возможности традиционной китайской цивилизации к концу минской эпохи «перезрели», т.е., выявившись в полном блеске, были исчерпаны; к тому же, при периодических контактах с иностранцами европейского происхождения и некотором знакомстве с информацией о внешнем мире режим в целом придерживался изоляционистской политики. Иными словами, при сохранении традиционного уклада жизни развитие китайской культуры стало невозможным: после высшей точки бывает только спад и стагнация, без подпитки свежими веяниями они только усугубляются. При нарастании количества и разрушительного характера социальных восстаний все это и привело к падению династии Мин под ударами завоевателей-маньчжуров. С этим утверждением можно согласиться лишь отчасти, поскольку в следующую эпоху - во времена империи Цин - тем не менее, происходили процессы, которые вряд ли можно свести к стагнации.

Что касается распространенной характеристики минской живописи как застывшей, не развивающейся, мертвой, то, по мнению автора, мнение это неверно.

Во-первых, новации как главный критерий художественности произведения были признаны таковыми только в Новое время и только на Западе. Знаменитый культуролог Умберто Эко отмечает: «В значительной мере 
искусство было и остается “повторяющимся”. Понятие безусловной оригинальности - это понятие современное, родившееся в эпоху романтизма» [6]. Культ новизны - чисто европейское изобретение, причем поздней эпохи, а судить культуру следует по ею признаваемым критериям. Любопытно, что и в европейском Средневековье устойчивость, повторяемость мотивов и сюжетов (например, в сказках, эпосе, легендах о святых), как указывал крупный российский медиевист А.Я. Гуревич, были для людей доказательством их подлинности [7, с. 46 - 99]. Совершенно то же может быть сказано и о визуальных видах искусства.

Во-вторых, работа в рамках канона ведет к изощренности и утонченности живописных методов: не утверждаем же мы, что икона, написанная в византийском стиле, устарела и у нее нет будущего; существование ярких современных иконописцев опровергнет такое суждение сразу и несомненно.

B-третьих, литературная центонность как стихотворная форма, составленная из известных цитат других стихотворений, известна со времен древних греков. Цитата вообще присуща любой художественной традиции. В то же время центонность в широком смысле как «цитатность» распростра- нена в стилистике постмодернизма, в том числе в его визуальных произведениях. С точки зрения Умберто Эко, постмодернизм с его цитатностью - неизбежный завершающий этап в конце всякой эпохи развития, ибо, когда кажется, что «все уже сказано (изображено)», остается только играть цитатами великих текстов и писать вариации великих картин: «постмодернизм - не фиксированное хронологически явление, а некое духовное состояние <...>. В этом смысле правомерна фраза, что у любой эпохи есть собственный постмодернизм, так же как у любой эпохи есть собственный маньеризм <...>. По-видимому, каждая эпоха в свой час подходит к порогу кризиса <...> раз уж прошлое невозможно уничтожить, ибо его уничтожение ведет к немоте, его нужно переосмыслить...» [8].

Установление династии Цин и развитие страны под ее управлением создало благоприятные социально-экономические условия для обновления художественной жизни Китая. Достаточно быстрая «китаизация» династии, толерантное отношение к китайской культуре и западноевропейским новациям подготовили формирование другой эпохи в развитии придворной живописи.

\section{Библиография:}

1. Неглинская М.А. Шинуазри в Китае: цинский стиль в китайском искусстве периода трех великих правлений (1662-1795) / М.А. Неглинская. М.: Спутник+, 2012. 478 с.

2. Китайский классический сборник: простое изложение истории династии Мин. Куньмин: Чэнгуан Чубаньшэ, 2014. 389 с.

3. Цинский двор: 1 / Под ред. Ван Синьлуна. Пекин: Чжунго Сицзю, 2009. 231 с.

4. Ткач Сергей. Христианство в Китае/Сергей Ткач [Электронный ресурc]. - Режим доступа: http://www. apologia.ru/Inkulturizatsija/Christianity_in_China (дата обращения 03.01.2016).

5. Дацышен В.Г. Христианство в Китае: история и современность / В.Г. Дацышен. М.: Научно-образовательный форум по международным отношениям, 2007. 240 с.

6. Эко Умберто. Инновация и повторение. Между эстетикой модерна и постмодерна/Умберто Эко [Электронный ресурс]. - Режим доступа: http://www.gumer.info/bibliotek_Buks/Culture/Eko/Inn_Povt.php (дата обращения 03.01.2016).

7. Гуревич А.Я. Проблемы средневековой народной культуры / А.Я. Гуревич. М.: Искусство, 1981. 359 с.

8. Эко Умберто. Заметки на полях «Имени розы» / Умберто Эко [Электронный ресурс]. - Режим доступа: http://www.ido.rudn.ru/philosophy/chrest/3-11.html (дата обращения 28.01.2016).

\section{References (transliterated):}

1. Neglinskaya M.A. Shinuazri v Kitae: tsinskii stil' v kitaiskom iskusstve perioda trekh velikikh pravlenii (16621795) / M.A. Neglinskaya. M.: Sputnik+, 2012. 478 s.

2. Kitaiskii klassicheskii sbornik: prostoe izlozhenie istorii dinastii Min. Kun'min: Chenguan Chuban'she, 2014. 389 s. 
3. Tsinskii dvor: 1 / Pod red. Van Sin'luna. Pekin: Chzhungo Sitszyu, 2009. 231 s.

4. Tkach Sergei. Khristianstvo v Kitae/Sergei Tkach [Elektronnyi resurs]. - Rezhim dostupa: http://www.apologia. ru/Inkulturizatsija/Christianity in_China (data obrashcheniya 03.01.2016).

5. Datsyshen V.G. Khristianstvo v Kitae: istoriya i sovremennost'/ V.G. Datsyshen. M.: Nauchno-obrazovatel'nyi forum po mezhdunarodnym otnosheniyam, 2007. $240 \mathrm{~s}$.

6. Eko Umberto. Innovatsiya i povtorenie. Mezhdu estetikoi moderna i postmoderna/Umberto Eko [Elektronnyi resurs]. - Rezhim dostupa: http://www.gumer.info/bibliotek_Buks/Culture/Eko/Inn_Povt.php (data obrashcheniya 03.01.2016).

7. Gurevich A.Ya. Problemy srednevekovoi narodnoi kul’tury / A.Ya. Gurevich. M.: Iskusstvo, 1981. 359 s.

8. Eko Umberto. Zametki na polyakh «Imeni rozy» / Umberto Eko [Elektronnyi resurs]. - Rezhim dostupa: http:// www.ido.rudn.ru/philosophy/chrest/3-11.html (data obrashcheniya 28.01.2016). 